\title{
Depression ... Just What I Thought
}

\author{
John P. Barbuto, MD
}

$\mathrm{J}$ uliet had it right. Bemoaning her parents' opposition to her romance with Romeo based solely on his family name, she cries, "O, be some other name! What's in a name? That which we call a rose, by any other name would smell as sweet." ${ }^{1}$ Juliet's angst centers on the profound effect of a name.

In the June 2008 issue of JMCP, Khandker and colleagues provide information regarding the pharmacy and medical costs associated with switching between venlafaxine and a selective serotonin reuptake inhibitor (SSRI) as antidepressant therapy for the treatment of major depressive disorder. ${ }^{2}$ In Khandker et al.'s work we see an interesting examination of a foreground topicthe drug and medical costs that are associated with switching antidepressants. Yet, immediately in the background are some fascinating questions and interesting implications. They hinge on the label "depression."

"Depression" is a word. It is a word that correlates to certain symptoms. We presume (or hope) it also correlates to a unified or consistent pathophysiology. Yet, is this presumption true? Certainly in genetics work, it is common knowledge that markedly different gene abnormalities, on entirely different chromosomes, may lead to the same clinical phenotype (a cluster of symptoms). Yet, in "depression," it seems we often proceed with the hypothesis that similar phenotype results from similar biochemical underpinnings.

For patients with "depression" who switch medication classes, Khandker et al. report that either way the switch occurs (from SSRI to venlafaxine or vice versa), there is a reduction in the patient's health care costs following the switch. And the cost benefits of switching are similar either way it occurs. What does this finding imply with regard to pathophysiology, and what does this imply in regard to our labeling of "depression?"

Of necessity, psychiatry has long been plagued by almost exclusive diagnostic reliance on symptoms. The Diagnostic and Statistical Manual of Mental Disorders (DSM)-IV has been called "a collection of symptoms turned into syndromes," and the proposed revision (DSM-V) was recently criticized for heavy influence from the pharmaceutical industry. ${ }^{3}$

Khandker et al. performed their administrative claims analysis on several subgroups of patients who are all considered (for purposes of their study) to have "major depressive disorder." They included several subgroups defined using International Classification of Diseases, Ninth Revision, Clinical Modification (ICD9-CM): (1) major depressive disorder single episode (296.2x); (2) major depressive disorder recurrent episode (296.3x); (3) dysthymic disorder (300.4); and (4) depressive disorder not elsewhere classified (311). The study of these patients was approached from the vantage point that initial use of either of 2 classes of antidepressant (SSRI vs. venlafaxine) produced insufficient effect, and a switch to the other category was implemented. But, the outcome was similar regardless of which way the switch went. So, do Khandker et al.'s findings suggest realworld biological equivalence of the 2 classes in the treatment of depression? Or, do these findings suggest a lack of either treatment option to "hit the nail on the head?"

In the clinic, patients with psychiatric disease are present with these symptoms. We hypothesize that these symptoms stem from a bodily state. We hypothesize that this state represents some disorder that shares common elements among patients. Thus, we give a unifying diagnosis: "depression." But, are all of our hypotheses warranted?

Citing other research, ${ }^{4}$ Khandker et al. introduce their article with the claim, "Despite the availability of a wide array of antidepressants to treat depression, between $30 \%$ and $50 \%$ of patients with major depression fail to respond to an initial course of antidepressant therapy." ${ }^{2}$ If we presume that "depression" is a similar phenomenon in patients, why then-armed with a broad range of pharmacological choices-do between one third and one half of patients fail initial therapy regardless of which biochemical approach is taken? And, with this question in mind, why do the authors observe an approximately two thirds reduction in health care costs when the initial drug is switched-regardless of which direction the switch goes?

We chase the symptoms with pills. Then we compare the costs of the pills. Yet, the scientist in us asks, "At 'the end of the day' is the greatest benefit from the pills themselves, or from just giving the pills?" Where is the connection between pathophysiology and the ability of medication to improve a patient's clinical and economic outcomes?

Also in the June 2008 issue of JMCP, Curtiss and Fairman further dissect the article by Khandker et al. and draw our attention to several limitations of this research report, including the apparent diversity in the severity of illness of patients with at least 1 medical claim for "depression," as evidenced by the wide range in medical costs, from $\$ 0$ to more than $\$ 2$ million per patient per year. ${ }^{5}$ This analysis also makes us wonder about the label "depression."

So, I wonder how well the name "depression" applies to the 48,950 patients considered by Khandker? We comfort ourselves by applying diagnostic names, presuming we have thus understood an illness. But I wonder, "What's in a name?"

\section{Author}

JOHN P. BARBUTO, MD, is Director, Outpatient Neurology, HealthSouth Rehabilitation Hospital, 8074 South 1300, East Sandy, UT 84094. Tel.: 801.565.6500; E-mail: doctorbarbuto@comcast.net 


\section{Depression ... Just What I Thought}

\section{DISCLOSURE}

The author reports no conflict of interest related to the subject of this commentary.

\section{REFERENCES}

1. Shakespeare W. Complete Works of William Shakespeare. Bishopbriggs, Glasgow: HarperCollins Publishers; 2006:960.

2. Khandker RK, Kruzikas DT, McLaughlin TP. Pharmacy and medical costs associated with switching between venlafaxine and SSRI antidepressant therapy for the treatment of major depressive disorder. J Manag Care Pharm. 2008;14(5):426-41. Available at: www.amcp.org/data/jmcp/JMCP_ June08Web_426-441.pdf.
3. Carey B. Study finds a link of drug makers to psychiatrists. New York Times. April 20, 2008. Available at: www.nytimes.com/2006/04/20/ health/20psych.html?_r=1\&scp=3\&sq=tufts+drug+firms+\&st=nyt\&oref= slogin. Accessed July $\overline{5}, 2008$.

4. Brent D, Emslie G, Clarke G, et al. Switching to another SSRI or to venlafaxine with or without cognitive behavioral therapy for adolescents with SSRI-resistant depression: the TORDIA randomized controlled trial. JAMA. 2008;299(8):901-13. Available at: www.pubmedcentral.nih.gov/ picrender.fcgi?artid=2277341\&blobtype=pdf. Accessed July 7, 2008.

5. Curtiss FR, Fairman KA. Switching antidepressant drug therapy helps some patients some of the time-What TORDIA, STAR*D, and observational research have taught us about treatment-resistant depression. J Manag Care Pharm. 2008;14(5):468-73. Available at: www.amcp.org/data/jmcp/ JMCP_June08Web_468-473.pdf. 